\title{
Psychological Aspects of Cyberspace
}

\author{
Maja Živko \\ Department of Information Sciences \\ Faculty of Humanities and Social Sciences, University of Zagreb \\ Ivana Lučića 3, 10000 Zagreb, Croatia \\ mazivko@ffzg.hr
}

\section{Summary}

This paper shows that cyberspace has both positive and negative aspects from a psychological point of view. The positive aspects are, temporal flexibility, no limitation of space, the speed of exchanging information, social multiplicity, textual communication, recording ability, entertainment, the empowerment of human potential, equality, and the diminution of the so-called "halo effect". Whereas, the negative aspects are, misinterpretations caused by a lack of sensual integration, the filtering or absorbing of information, frustration caused by technical difficulties, the redefining of identity, "cyberstalking", behavioural disinhibition, and "cyber addiction". Some aspects can be both positive and negative such as, anonymity, distance learning and online psychosocial-globalization.

Key words: cyberspace, self-disclosure, anonymity, asynchronous, synchronous communication, network brainframe, Internet addiction

\section{Introduction}

In its current usage, the term "cyberspace" is a global network of interdependent information technology infrastructure, telecommunications networks and computer-processed systems. Cyberspace represents "computer-based" channels, "computer networks," and "virtual reality". The term has become a conventional name to describe anything associated with the Internet. This is how the term is understood in this paper. Through this electronic media individuals can communicate, work, create artistic media, read journals, educate themselves, play games, take part in conferences, exchange ideas, etc. In psychology cyberspace is also labelled as the "network of minds". In cyberspace we are able to exchange and share our ideas with others to develop them. In other words, our minds communicate and share ideas with each other. In the "network of reality" there is a dialogical development of meaning. Suler (2007) argues that, "As people view an e-mail, web page or instant message written by an online companion, some people truly feel that their minds are connected to or even blended with the minds of the others". 
In the "network of minds" there is an interaction between minds. According to Barak (2008), "cognition in cyberspace is something that happens "between" rather than "inside" subjects and it is a coordinated activity."

Most importantly, the cybernetic brainframe has turned into an "information producer", whilst the individual brainframe has morphed into an "inter-brainframe".

Therefore, the aim of this paper is to describe both the positive and negative aspects that cyberspace (or the so-called network of minds) has brought into our society from a psychological perspective. It must be stressed that the following aspects discussed below are only one part of a much greater range of issues in this dynamic field.

\section{Positive aspects of cyberspace}

Clearly the positive aspects of cyberspace are temporal flexibility, no limitation of space, social multiplicity, textual communication, recording ability, the speed of information exchange, entertainment, the unlimited amount of information provided, the empowerment of human potential, equality, and the diminution of the so-called "halo effect".

\subsection{Temporal flexibility}

In cyberspace time is flexible: communication in cyberspace can be synchronous through chat rooms, in metaworlds where graphical personas or people appear inside a movie set as avatars, or in asynchronous form through the use of e-mails and discussion forums. Asynchronous communication does not require people to interact with each other at the same time. In both asynchronous and synchronous forms of communication (with the exception of video conferencing and Internet-based calls), time is stretched. In an online chat, people have anything from several seconds to a minute or more to reply to another person - this being a significantly longer delay when compared to face-to-face meetings. In e-mails, blogs, and newsgroups, people have hours, days, or even weeks to respond. This gives people time to think about what they want to say and compose their replies in exactly the way they want. This distant communication enables some people to be more expressive, organized, and creative in writing messages.

\subsection{No limitation of space}

Geographical distance does not exist in cyberspace as computer networks enable people to interact with each other no matter where they are.

\subsection{Social multiplicity}

Dealing with the relative ease that a person can communicate with hundreds, perhaps even thousands of people. For instance, by posting a message on a blog, 
M. Živko, Psychological aspects of cyberspace

discussion board, or social networking site, which is read by countless numbers of other users, people are connected with other people in an instant.

\subsection{Textual communication}

Despite the lower sensory quality of text communication, written forms of interaction should not be underestimated as a powerful means of self- expression and interpersonal communication. E-mails, online chats, instant messaging, SMS', and blog's continue to be the most common forms of social interaction. Typing one's thoughts and reading those of another person is a unique way to present a personal identity, perceive the identity of the other online counterpart, and establish a relationship. Some people feel that they can express themselves better in writing.

\subsection{Recording ability}

A clear and practical advantage of any typed form of communication is that text can always be saved (on disks, tapes), printed or stored as a standard file, which is not possible in reality where people almost always have to rely on their memory.

Thanks to this recording ability, people in cyberspace can experience and reevaluate any part of their communication they wish over and over. They can also use quoted text as feedback to others.

\subsection{Speed of exchanging information}

In cyberspace there is also the ease and speed with which messages are transmitted across huge distances. People can send and receive messages in a very short time. This is very important, especially in business, where people have to communicate quickly with each other as much as possible.

\subsection{Entertainment}

The Internet offers entertainment to people in the form of movies, video games, music, online books, magazines, and online chatting. The Internet has therefore become a source of entertainment for millions of people around the world because it offers many cheap and easily accessible forms of entertainment. ${ }^{1}$

\subsection{Unlimited amount of information provided}

Cyberspace has seen people's ability to better inform themselves improve dramatically, if they should desire. Through a large number of online newspapers, magazines, books and bulletin boards people can find any information they want in unlimited amounts.

\footnotetext{
${ }^{1}$ Entertainment can sometimes have negative aspects, e.g. video games can encourage violence aggression, and fear.
} 


\subsection{Empowerment}

The Internet also leads to "empowerment", because there are powerful effects from its usage on the way individuals think. We can say empowerment when referring to the full development of human potential, which means freedom from biases, compulsions, hostility, self-doubt, lack of understanding, and an unreflective acceptance of ideologies. The Internet allows individuals to build on their own expertise and ideas. Thus, helping develop creativity and personal identity.

\subsection{Equality}

The Internet does not discriminate against or marginalize people by gender, class, or ethnicity. It gives people the opportunity to show their own ideas, if they choose too, by creating their own sites on the World Wide Web. Anybody can publish their opinions, needs, interests, and aspirations on the Internet.

\subsection{Diminution of the "halo effect"}

In cyberspace people cannot judge the personality of another person by his or her physical appearance. This electronic platform distracts us from the effects of any face-to-face interaction, because the perception of one trait (i.e. the appearance or characteristic of a person or object) is not influenced by the perception of another trait (or several traits) of the person or object in question.

\section{Negative aspects of cyberspace}

Apart from the obvious positive aspects in the online world, there are several negative aspects that need to be mentioned such as a lack of sensual integration, an absorption of information without filtration, any frustration caused by technical difficulties, the redefining of identities, cyberstalking, behavioral disinhibition, feeling that happiness belongs to others, cyber-addiction, etc.

\subsection{Lack of sensual integration}

Through text-based types of communication the lack of audio-visual sensors such as a change in the tone of our voice, facial expressions, or body language can cause misinterpretations. For instance, tactile stimulation, as well as gustative and olfactive feelings do not exist online. ${ }^{2}$ However, cyberspace also allows for various combinations of text, audio, and visual-based communication forms. With so many combinations available, people can hear but not see each other, read texts from each other and see each other but not hear each other, or they can see and hear each other but not bother each other with a written form of communication. In some cases written communication can cause misunder-

\footnotetext{
${ }^{2}$ In cyberspace sensory integration is missing-we see, we hear, but we don't touch, smell or taste.
} 
M. Živko, Psychological aspects of cyberspace

standings and conflicts. ${ }^{3}$ However, in today's multimedia chat environment, misunderstandings and conflicts are lowered because it gives us the opportunity to use an audio-visual form of communication as well. Through the use of various software programs and applications, our voice can be examined more carefully for subtle emotions and meanings that allow people to review their communication between each other.

\subsection{Absorbing information without filtering it}

Put simply, not all information on the Internet is good, true, valid, or has quality. Individuals can become mere consumers or absorbers of any electronic data flowing through the Internet. These networks lead individuals to expect that they can find a tool that can quickly solve any problem. People impatiently look for technological solutions rather than taking the time to reflect on issues, ponder alternative solutions, and critically analyze problems. Therefore, it is vitally important to filter information and analyze it critically, rather than absorb it passively.

\subsection{Frustration caused by technical difficulties}

Electronic media is not immune to problems with student-technology interactions, such as any frustrations caused via technical and connection difficulties, and shutdowns. A student's progress during a course, at university for example, can come to a halt due to frustrations with technology. As Wilken (2004) opines "it seems that students become paralyzed until the technical issue is resolved. Students feel abandoned or in some way locked out when they become disconnected from the course due to technical difficulties".

\subsection{Redefining identity}

Another thing that can occur in cyberspace is a "redefinition of identity." One thing that is particularly troublesome with the formation of identity is the way that young people are being shaped by the Internet. The entertainment and information options that these technologies enable, such as Internet support, enhance, and increasingly define their identities. The Internet can also distort ideas, and manipulate receivers, especially among the youth of today that has a tendency to accept radical ideologies without any critical thinking.

\footnotetext{
${ }^{3}$ Lacking audio-visual effects, an e-mail message, blog, or newsgroup post can be ambiguous. When people read a typed message, there is a strong tendency to project -sometimes unconsciously - their own expectations, wishes, anxieties, and fears into what the other person wrote. Psychoanalytic thinkers call this "transference." Distorting the other person's intended meaning can lead to misunderstandings and conflicts.
} 


\subsection{Feeling that happiness belongs to others}

Social networking sites (e.g. Facebook, Twitter, etc.) can cause sadness and loneliness. Looking at the "happy" photos of others can lead to some people convincing themselves that other people lead a perfect life and, in turn, they overestimate other people's happiness. Therefore, social networking sites can lead to frustration, sadness and loneliness, as well as the feeling of being a "loser".

\subsection{Cyberstalking}

Online harassment and cyberstalking are quite common on the Internet. "Cyberstalkers" can target their victims through several means, including, chat rooms, message boards, discussion forums, and e-mail. Cyberstalking can be occur in a variety of ways, such as sending threatening or obscene e-mails, spamming (in which a stalker sends the victim a multitude of junk e-mail), live online chat harassment or flaming (online verbal abuse), leaving abusive or offensive messages on message boards or guest books, sending electronic viruses or unsolicited e-mail and so on.

\subsection{Behavioral disinhibition}

It is quite well known that people in cyberspace engage in behavior they would normally deem inappropriate in the real world, due to the fact that they feel more unrestrained. The Internet encourages non-conform, sometimes aggressive, and even unrestrained behavior. The most general cause of problematic behavior is when Internet usage is related to the so-called phenomenon of "behavioral disinhibition." In face-to-face forms of communication, individuals are constrained by the existing social rules that govern interpersonal interaction, immediate negative feedback, and any visible consequences of their inappropriate behavior. Moreover, they are constrained by the social sanctions that would follow after conducting such behavior. In the e-based, and by definition anonymous world, users are often unaware of their identities and personalities and thus can easily ignore the negative consequences of their risky or otherwise unacceptable behavior. This contributes to the expression of anger or aggression and inappropriate self-disclosure.

\subsection{Cyber-addiction}

Davis (2001) distinguishes between two types of Internet addictions that he divides into specific and general. Specific addictions are an overuse or abuse of any content-specific functions on the Internet (e.g. gambling, stock trading). A general addiction is a multidimensional overuse of the Internet that can result in negative personal and professional problems. A person with a general addiction is drawn to the experience of being online and demonstrates a preference for virtual, rather than face-to-face, interpersonal communication. 
M. Živko, Psychological aspects of cyberspace

For example, the popularity of the social networking site Facebook has led to some serious addiction problems. In psychological literature a term "Facebook addiction" has already been coined. The main issue is that people do not notice the terribly high amount of time and energy that they spend on Facebook. More and more links on web pages invite "sharing" and other types of Facebook-related activities. On the one hand, people use Facebook activities that one could call creative, self-revealing or social, but on the other hand, they could also easily become addicted to it. "Facebook Addiction Disorder" (FAD) is a situation where using Facebook becomes a compulsion and sees people spend all their time logged on to the social networking site whilst ignoring their real social life (friends, family, work.)

\section{Psychosocial globalization, e-education and anomymity as positive or negative aspects?}

\subsection{Online psychosocial globalization}

Cyberspace develops web-relationships. Through this new medium individuals can exchange information and find or form groups that share similar interests. Cyberspace is a "global village or virtual community" (Poole 1997, Wresch 1997). Through social networking sites and virtual worlds (e.g. Second Life, World of Warcraft) people with common interests can share information, work together, tell stories and jokes, discuss politics, help each other, or play games. In cyberspace people also communicate one-to-one and create online groups (e.g. interest and hobby groups, self-help groups, special interest consumer groups). All members of cyberspace have the opportunity to be involved in a society, to which they belong. This is valuable for those who hardly ever communicate with others in the real world, such as seniors whose work and social circles may have become narrowed, shy and timid people, and people who have trouble finding people with similar interests.

Nonetheless, online globalization can also have some negative effects. Cyberspace is exclusively accessible only to those who have the possibility of communicating through e-based media. However, in reality there are still a lot of people with no access to the Internet that are not trained in e-technologies and have no computer skills. On the one hand, there is a global online community, whilst on the other hand, there are those who are disconnected from the Internet world. In this respect, the e-world can also lead to a broadening of existing social inequality.

\subsection{Online education}

Thurlow and Lengel label a person who learns via computers a "cyber student" (2004:2). The Internet helps cyberstudents gain new skills. Via online books, videoconferences, and discussion forums, individuals can learn about new fields, methods, and acquire new skills. Motivation for e-learning seems to be much stronger than offline learning because of the way of teaching, such as 
multimedia platforms, quizzes, games, an easy way to find knowledge sources online, synchronous chatting, discussion forums, asynchronous messages, and e-mail attachments. Individuals can help and support each other through interactions with each other and with their teachers by sharing knowledge and information. In addition, they can also interact with each other through social media platforms such as Facebook, Youtube, virtual social worlds (e.g. Second Life), and virtual game worlds (e.g. World of Warcraft), where people can combine entertainment with education.

In contrast, online education can also have some negative aspects, for example, less liveliness. Classroom discussions can be very stimulating and sometimes much more effective than learning over the Internet. Real-time discussions allow for an instant two-way teacher-cyberstudent interaction and provide the richness of interpersonal interactions so often missing in distance education classes.

\subsection{Anonymity}

The Internet allows people to conceal their real identity and personal information under false names and identify details which encourage people to express themselves more freely and sincerely than they would in a face-to-face interaction (the so-called "online disinhibition effect). This is because of the fact that they cannot be seen nor heard, which in turn allows people to potentially open up and say things that they normally would not say in the "real world". Thanks to anonymity, self-disclosure and intimacy can be accelerated because people can sometimes disclose more personal, intimate, and sensitive information in the virtual world. In an e-based environment people are more likely to make deeper disclosures about themselves than in reality. Being anonymous in cyberspace is also helpful to those who live in countries where freedom of speech and access to the press are not guaranteed. It creates an open forum to inform others without any danger to themselves.

Anonymity has negative sides too. The physical distance between web participants leads to disinhibited behaviour, because in cyberspace a person can create many identities. Strangers can meet, exchange some right or wrong information and more or less shift their personality so to speak. For instance, a man creates a female identity, or a high school student claims to be an engineer. Internet users are not accountable for what they say, and therefore, positive personal relationships on the Internet are also rare and infrequent.

\section{Conclusion}

This article discusses both the positive and negative sides of the Internet world, called cyberspace. Cyberspace allows us to freely choose between synchronous and asynchronous alternative communication, enables us to communicate with thousands of people without the limitations of time and space, present our identity in a written form, record communication, watch movies, play games, listen 
to music, read books and magazines, chat, and it empowers our identity to be equal with others. On the other hand, in cyberspace we absorb a lot of information without filtering it and often experience technical difficulties that can cause frustration. We are sometimes manipulated by others on the Internet, or feel that happiness belongs to others. Another dangerous aspect can be e-base stalking by other e-users, called cyberstalking. The anonymity that the virtual world offers can lead us to communicate with dangerous people without being aware of it. Internet users are also globalized in a psychosocial network that leaves those with no access to the Internet disadvantaged and socially crippled. To conclude, cyberspace has become an important part of our everyday life that has both positive and negative aspects that we need to be aware of. Can we ever create a cyberspace world that would function with the lowest possible amount of negative aspects? It is up to all of us to build a new improved future cyberspace where the positive aspects will outweigh the negative ones.

\section{References}

Baldwin, E. E. Family empowerment as a focus for home economics education. // Journal of Vocational Home Economics Education. 8 (1990)2; 1-12

Baldwin, E. E. Transformative professional practice: Overcoming ambivalence, building community, Kappa Omicron Nu FORUM. 8 (1995),2; 21-37

Basu, Subhajit, J. R. Regulating cyberstalking. //Journal of Information. Law \& Technology (JILT)2, 2007

Brown, M. M. Philosophical studies of home economics in the United States, Basic ideas by which home economists understand themselves. East Lansing: Michigan State University, College of Human Ecology, 1993.

Brown, M. M., \& Baldwin, E. E. The concept of theory in home economics. East Lansing, MI: Kappa Omicron $\mathrm{Nu}, 1995$.

Barak, A. Psychological Aspects of Cyberspace, Cambridge University Press, 2008.

Caroly, S. Wilken. Computer Mediated interaction in a Distance Education. 2004. http://www. kon.org/archives/forum/11-1/wilken.html (2004-08-26)

Cohen, E. Five clues that you are addicted to facebook. 2009. http://edition.cnn.com/2009/ HEALTH/04/23/ep.facebook.addict/index.html (2009-04-23)

Cyberspace. 2011. http://en.wikipedia.org/wiki/cyberspace (2011-09-5)

Cyberpsychology, Behavior and Social Networking. 2010. http://www.liebertpub.com/products/ product.aspx?pid=10 (2010)

Davis, J. A cognitive-behavioral model of pathological Internet use, 2001.

Gackenbach, J., Psychology and the Internet, Academic Press, 2007.

Green, T. F. The formation of conscience in an age of technology, American Journal of Education, 94 (1984)1; 1-32

Foster, D. Community and identity in the electronic village. In D. Porter (Ed.), Internet culture. New York: Routledge, 1997

Friedman, M. Internet Addiction: A public Health Crisis, 4.22.11

Hadžiselimović, Dž., Plavšić, M., Pregrad, J., Rusijan Ljuština, V. Psihologija mediji etika, Pula: Naklada Slap, 2009.

Haugtvedt, P., Machleit, K., A., Yalch, R., F. Oline consumer psychology. Taylor\&Francis eLibrary, 2009.

Joinson, A., McKenna, K. The Oxford Handbook of Internet psychology. Great Britain: Oxford University Press, 2007.

Joinson, A., N. Understanding the Psychology of Internet behavior. Palgrave, 2003 
De Kerckhova, Lumsden. The Alphabet and the brain. Springer, Verlag, 1988

Journal of Psychosocial Research on cyberspace http://www.cyberpsychology.eu.(2010)

Kimberly, S., Young, Cristiano Nabuco de Abreu. USA: Internet addiction, John Wiley\&Sons, 2010.

Libby, C. The Anti-social Network: Is Facebook Making us Sad? 2011. http://www.slate.com (2011-01-26)

Morgaine, C. A., A language of empowerment, Home Economics Forum, 6 (1993)1; 15-20

Nnamdi G. O. Facebook addiction. USA: Ice Cream Melts Publishing, 2009.

Poole, B. J. Education for an information age: Teaching in the computerized classroom. Boston, MA: WCB/McGraw-Hill, 1997

Rehm, M. Empowering the creative spirit: An inquiry into the role of home economics education. //Journal of Vocational Home Economics Education. 7 (1982)2; 1-12

Rehm, M. An aesthetic approach to empowerment. Home Economics FORUM, 6 (1993)2; 26-39

Rehm, M. The Internet as a course Practical Problem: Empowerment in the Electronic Global village. 2004. http://www.kon.org/archives/forum/11-1/rehm.html (2004-08-26)

Seel, J. Plugged in, space out, and turned on: Electronic entertainment and moral mindfields. // Journal of Education. 179(1997), 3; 17-32

Riva, G., Galimberti, C. The Psychology of Cyberspace. //New ideas in psychology. 15 (1997)2; 141-158

Staiger, J. Media reception studies. New York and London: New York University Press, 2005.

Suler, J. The Psychology of Cyberspace Relationships. 2008. http://www.enotalone.com (200801-02)

Suler, J. Psychology of Cyberspace - The Basic Psychological Features of Cyberspace. 2005. $\mathrm{http}: / /$ users.rider.edu/ suler/psycyber/basicfeat.html (2005-01-8)

Thurlow, C. C., Lengel, L., Tomic, A. Computer Mediated Communication. USA: Sage Publications, 2004

Walace, P. The Psychology of the Internet. Great Britain: Cambridge University Press, 1999

Wresch, W. A teacher's guide to the information highway. Upper Saddle River, NJ: PrenticeHall, 1997. 